\title{
Farklı amaçlarla yapılan üst GiS endoskopisinde ektopik pankreas görülme oranı
}

\author{
Ectopic pancreas prevalence rates in upper GI endoscopy for different etiologies
}

Agil AĞAKISsiYYEV, M. Sait DAĞ, Hakan ÇAM, Nimet YILMAZ, Musa AYDINLI, M. Taner GÜLŞEN, İrfan KORUK

Gaziantep Universitesi Tip Fakültesi Gastroenteroloji Bilim Dal, Gaziantep

Ektopik pankreas genellikle tesadüfen saptanan nadir bir konjenital anomalidir. Sıklıkla insidental bir bulgudur ve gastrointestinal sistemin farklı bölgelerinde saptanabilir. Bu çalışmada amacımız üst endoskopisi yapılan hastalarda ektopik pankreasın sıklı̆ıın belirlemektir. Ektopik pankreas genellikle endoskopi veya cerrahi esnasinda tesadüfen tespit edilir. Gastrointestinal stromal tümörden sonra midedeki ikinci en sik subepitelyal lezyondur. Literatürde ektopik pankreas sıklığ1 \%0,2 olarak verilmiştir. Bizim serimizde de üst gastrointestinal sistemde endoskopik olarak slklık \%0,2 tespit edilmiştir.

Anahtar kelimeler: Ektopik pankreas, ektopik pankreas sıklığı
Ectopic pancreas is a rare congenital anomaly. It is often an incidental finding and can be found at different sites in the gastrointestinal system. The aim of this study was to determine the ectopic pancreas incidence in patients undergoing upper endoscopy. Ectopic pancreas is usually detected incidentally during endoscopy or surgery, and ectopic pancreasit is the second most common epithelial lesion after gastrointestinal stromal tumors. The prevalence of ectopic pancreas in the literature is approximately $0.2 \%$. In our series a frequency of $0.2 \%$ was determined in upper gastrointestinal endoscopy.

Keywords: Ectopic pancreas, prevalence of ectopic pancreas

bildirilmiştir (10). EP bazen pankreatit, kist oluşumu, ülserasyon, kanama, tıkanma sarılığı ve mide çıkışı tıkanıklığı ile ilişkili semptomlar üretir (11).

Aseptomatik ve komplikasyonların oluşmadığı durumda genellikle hematolojik tahliller ve biyokimyasal laboratuvar sonuçları normaldir (12).

Bu çalışmada amacımız üst gastrointestinal sistem (GIS) endoskopisi yapılan hastalarda ektopik pankreasın sıklığını belirlemektir.

\section{GEREÇ ve YÖNTEM}

Bu çalışmaya Gaziantep Üniversitesi Tip Fakültesi Gastroenteroloji Bilim Dalı Endoskopi Ünitesi'nde 01.01.201131.12.2012 tarihler arası farklı sebeplerle yapılan üst GIS endoskopiler dahil edildi. Ektopik pankreas ile uyumlu görünümü olan hastaların yaş, cinsiyet, ön tanı ve endoskopik bulguları kaydedildi. Uygun hastalarda endoskopik ultrasonografi (EUS) yapıldı ve varsa histopatolojik bulguları kaydedildi.

\section{BULGULAR}

Belirlenen tarihler arasında toplam 10.457 hastaya üst GIS endoskopi yapılmıs olup, bu hastaların $25^{\prime}$ inde $(\% 0,2)$ EP ile 
uyumlu görünüm izlenmiştir (Resim 1). Bu hastaların 12'si (\%48) erkek, 13’ü (\%52) kadındır. Yaşları 20-81 aralığında olup, median 31 yaştır. Ektopik doku hastaların l'inde özofagusta (\%4), 20'sinde antrumda (\%80), 4'ünde duodenumda (\%16) izlendi. 20 hastada (\%80) mukozal histopatolojik inceleme yapılmış olup bu hastaların 18'inde (\%90) kronik gastrit, 2 (\%10) hastada normal gastrik mukoza izlenmiştir. 8 hastada EUS yapılmış olup submukozada yerleşik hipoekoik oluşum izlenmiştir (Resim 2).

\section{TARTIŞMA}

EP genellikle endoskopi veya cerrahi esnasinda tesadüfen tespit edilir ve gastrointestinal stromal tümörden sonra midedeki ikinci en sık submukozal lezyondur (13). Literatürde EP total sıklığı \%0,2 olarak verilmiş olup (8) bizim serimizde de endoskopik olarak sıklık \%0,2 tespit edilmiştir. Bu haliyle bizim serimizdeki oran literatürle bire bir uyumludur.

Ektopik pankreas infant ve çocuklarda dahil $(2,14)$ her yaşda (12) görülebilse de 40-70 yaşlarda $(10,15)$ rastlanma sıklığ daha çoktur. Pediatrik hastalarda kadın cinsiyet hakim iken (16) yetişkinlerde görülme sılklığı erkeklerde daha yüksektir $(5,16)$. Erkek kadın oranı 3:1'dir. $(2,17)$. Bizim çalışmamızda ortanca yaş 31 olarak bulunmuştur. Ancak erkek kadın oranı arasında belirgin fark izlenmemiştir (\%48'e karşın \%52). Ektopik pankreas dokusu özofagusun distal ucundan kolona kadar sindirim sisteminin her yerinde bulunabilirken, sindirim kanalı dışında da lokalize yeri ve lezyona bağlı komplikasyonlar bildirilmiştir. EP ile bağlantılı semptomlar nadirdir, ancak mevcut olduğunda genellikle belirtileri peptik ülser veya pilor obstrüksiyonuna benzemektetir (18). Genellikle mide (\%25-38), duodenum (\%17-36), jejunumda (\%15-21) lokalize olur (19) ve nadiren de özofagus (20), safra kesesi, ampula Vateri (21), koledok (22), karaciğer (23), dalak, int-

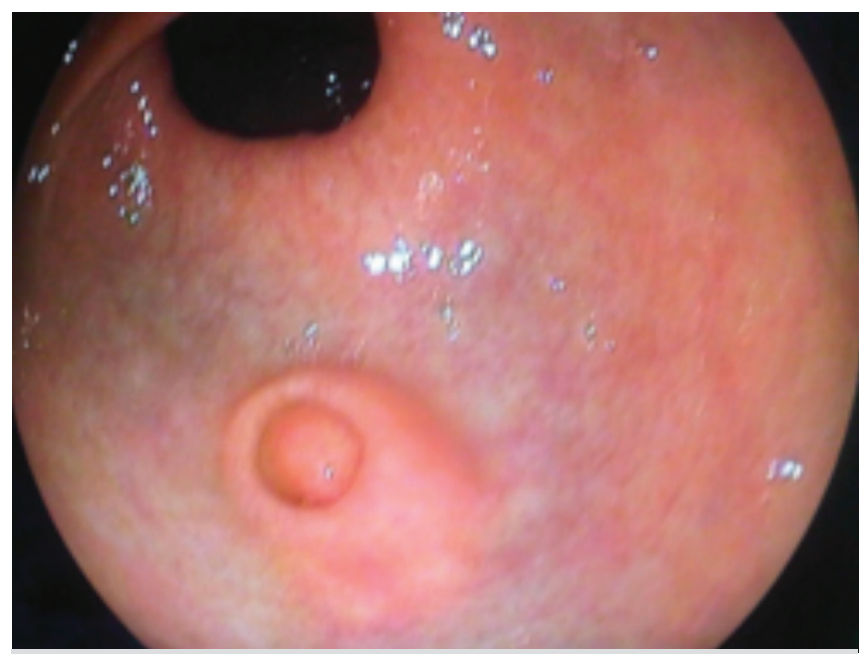

Resim 1. Ektopik pankreasın endoskopik görünümü raabdominal, mezenter $(10,24)$, mediasten $(24,25)$, akciğer (16), Meckel divertikülü $(16,26)$, omentum (12) gibi lokalizasyonlarda görülebileceği bildirilmiştir. Gastrik lezyonların yayılımı \%85-95 antrum (15) ön ve arka duvarda görülür (16).

Pankreasın heterotropisini ve patogenezini açıklamak için çeşitli teoriler ileri sürülmüştür. Literatürlerde bu teorilerden 2'si daha bariz savunulmaktadır: Farklı yer teorisi ("misplacement theory") ve metaplazi teorisi. Embriyolojik olarak pankreas ilk önce duodenumda endodermal dokunun invajinasyonundan gelişir (16). Ventral aspektden pankreasın baş kısmı, dorsal aspektden pakreasın korpus ve kuyruk kısmı gelişir (4). Farklı yer teorisinde ön bağırsağın rotasyonu zamanı gastrointestinal trakt boyu ilk önce pankreas dokusundan birkaç bölüme ayrılır ve sonunda heterotrop pankreatik doku kalır (12). Metaplazi teorisinde ise embriyogenez sirasında endodermin pankreas metaplazi bölgesinden submukozaya migrete olan pankreatik heterotopi bölgesi olduğu söylenir $(19,27)$. Scarpelli, pankreatik heterotopi açıklayan iki en olası teoriyi şöyle tanımlıyor: 1) ana pankreas dokusundan embriyonik tomurcukları ayrılması ve farklı yerde büyüme ile hızla büyüyen bağırsak duvarına nüfuzu sonucu; 2) pankreatik doku gelişimi ile gastrointestinal sistemin pluripotent embriyonik mezenkimal dokunun uygunsuz yerleşimi (28).

Histolojik olarak pankretik asinüsler, kanallar ve Langerhans adacıkları bulunduğu zaman tanı koymak zor değildir. Ilk histolojik tanı 1859'da Klob tarafından tanımlanmıştır (18). Heinrich 1909 yllında Heterotropik pankreasın histolojik ayırımında 3 tip önermiş (23) ama onun sınıflandırılması 1973 yllında Gaspar-Fuentes tarafından son şekline güncellenmiştir (12).

EP histolojik olarak 4 alt tipte incelenmektedir ve günümüzde sık kullanılır.

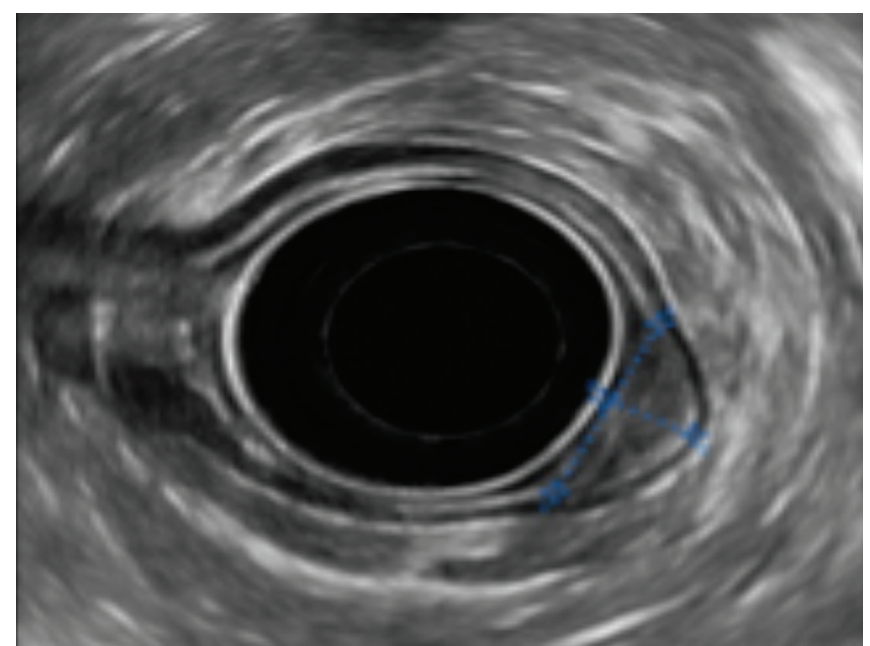

Resim 2. Ektopik pankreası olan hastanın endoskopik ultrasonografik görünümü. Submukozal yerleşimli hipoekoik $15 \mathrm{~mm}$ oluşum 
Tip 1: tipik pankreas dokusunda rastlanan asinüsler, kanallar ve adacık hücreleri ile normal pankreas görüntüsü oluşturur (komplekt heterotropi).

Tip 2: sadece pankreatik kanallar yapısında çeşitli kanaliküller şeklinde oluşur (kanaliküler heterotropi).

Tip 3: sadece asinüs dokosu ile karakterize (egzokrin heterotropi).

Tip 4: sadece adacik hücreleri ile karakterize (endokrin heterotropi)

Makroskopik olarak EP 1-4 cm çapında, lobullerden oluşan beyaz veya sarı noduler tümörlerin oluşumudur (3). Literatürde çapı 6 cm'den büyük EP lezyonuna çok az rastlanmaktadır. Shin ve ark. 2007 yllında, jejunal mezenterden kaynaklanan $20 \mathrm{~cm}$ çapında EP dokusunu (10), Türkiye'den Canbaz ve ark. proksimal jejunum mezenterinde lokalize $15 \mathrm{~cm}$ (24), Voboril pilor tıkanıklığına neden olan 9 cm (28) EP olgularını sunmuştur.

EP tanısı laboratuvar, görüntüleme ve diğer enstrümantal tanı prosedürlerin gelişmesine rağmen, spesifik markerler olmadığı için zordur. Tanıya her zaman endoskopik biyopsi veya rezeksiyon ile çıkarılan malzemenin histopatolojik incelenmesi ile gidilir (16). Bizim çalışmamızda bunlara ek olarak uygun hastalarda endoskopik ultrasonografi kullanılmış ve lezyon submukozal katmanda hipoekoik olarak görüntülenmiştir (Resim 2). Ayrıca tıpkı diğer subepitelyal lezyonların tanı ve takibinde olduğu gibi mukozal biyopsiler alınarak lezyonun mukozal ilişkisi ve patoloji olup olmadığı araştırılmıştır. Biyopsi alınan hastaların 18'inde (\%90) kronik gastrit, 2 (\%10) hastada normal gastrik mukoza izlenmiştir.

Mide baryumlu grafi ile klasik görüntülemede sensitivite ve spesifite sırası ile \%87,5 ve \%71,4'dür (6). Baryumlu çalışmada lezyon karakteristik olarak merkezi göbeklenmiş olarak görülebilir (12). Mide EP için bilgisayarlı tomografi (BT) bulguları teşhis için nonspesifik olmakla birlikte kontrastlı çok kesitli spiral BT incelenmesi ile lezyon ve lokalizasyonu gösterilebilir ama diğer submukozal tümörlerden ayırt edilemez (1).

GIS submukozal lezyonları genellikle intraluminal olarak normal mukoza ile örtülü kabarıklıklardır. Bu lezyonlar sıklıkla rutin özofagogastroduedenoskopi sirasında tesadüfen bulunmuştur. Endoskopi geniş tabanll, umblike subepitelyal lezyon şeklinde görülür (3) (Resim 1). Yüzey biyopsileri genellikle normaldir. Ayırıcı tanıda benign ve malign mide duvarı tümörleri, dışardan bası, intramural damarları ve ekstramural yapılardan bir dizi içerir (15).

Kapsül endoskopi ve tek barsak enteroskopi gibi yeni teknolojiler ameliyat olmadan önce ulaşlamayan ince barsak lezyonları saptamada kullanılmaktadır (19).
Lezyonlar endoskopik olarak tespit edilse bile, biyopsi genellikle submukozal lezyonları ortaya çıkarmak için çok yüzeysel ve bu durumda olduğu gibi sadece kronik inflamasyon gösterir. Bizim serimizde elde edilen histopatolojik bulgular da bu bilgilerle örtüşmektedir. EUS gastrointestinal sistemin subepitelyal lezyonlarının değerlendirilmesinde standart bir testtir. EUS ile çapı 0,5-2cm kadar submukozal heterotopik pankreas teşhis edilebilir ve ince iğne aspirasyon ile kombine edildiğinde sitolojik incelemesinde tanıda \%80-100 arasında bir duyarlılığa sahiptir $(1,19)$. Mide için spesifik olarak sırası ile \%73-17-10 olmak üzere submukoza, muskularis propria ve seroza tabakalarında yerleşim olur $(6,18)$. EUS'da EP genellikle hipoekoik ve kimi zaman sınırları düzensiz olarak görülür. Lezyon içinde anekoik alanlar duktal yapılar ile ilişkilidir (15). EP görüntülemesinde 3. ve 4. tabakada lokalize olunmuş (füzyon tip) ve sadece 3. tabakada lokalize olmuş (ayırıcı tip) karakteristik heterojen, hipoekoik alanlar görülür (16).

Doku örnekleri standart bir endoskopik biyopsi forsepsi kullanılarak elde edildiğinde EP histolojik tanısı genellikle zordur (32). EP düşünülen, üzeri normal mukoza ile kaplı lezyondan alınan biyopside histolojik olarak incelemede yaklaşık \%50 vakada normal olarak rapor edilmiştir (3). Ancak bir kaç seride EP durumlarında jumbo forseps ile alınan biyopsilerin tanıda daha çok yardımcı olacağı bildirilmişdir (12). Goto ve ark. EUS eşliğinde ince iğne aspirasyonu ile özofageal EP tanısı olgusunu sunmuştur (5).

Asemptomatik ve pozitif tanı alan hastalar tıbbi gözetim altında kalmalıdır ve periyodik olarak takip edilmelidir. Komplikasyonsuz, semptomatik hastaların lezyonları tercihen lokal rezeksiyon veya eksize olmalıdır. Endoskopik rezeksiyon, deneyimli ellerde ve gelişmiş ünitelerde uygun hastalarda yapılabilir ve bu tür vakalarda EUS kullanımı şarttır. Kanama, obstrüksiyon veya malignite şüphesi ile ilişkili lezyon durumlarında, uygun cerrahi yaklaşım tavsiye edilir (16).

Gastrik heterotopik pankreasta pankreatit, psödokist, adenom, insülinoma, nöroendokrin karsinom gelişebilir. Malign değişim sıklığı tam olarak bilinmemekle birlikte literatürde 30'un üzerinde bildirilen vaka mevcuttur. 12 olguyu içeren bir seride heterotropik pankreas dokusunda \%12,7 oranında kanser sıklığı bildirilmiştir (10).

Tıbbi veya endoskopik tedavi sonrası dirençli veya tekrarlayan semptomları olan vakalarda cerrahi yaklaşım alternatif olarak düşünülmektedir (29).

Kanama, ülserasyon, tıkanıklık ve invajinasyon gibi komplikasyonların ortaya çıktığı EP olgularında cerrahi tedavi endikasyonu mevcuttur (30). Tipik görünümü ve lokalizasyonu ile semptomatik lezyonlar, laparoskopi, endoskopi veya endoskopi eşliğinde minimal invaziv teknikler kullanılarak tedavi edilmelidir. Perioperatif biyopsi de tavsiye edilir (31). 
Başka sebeplerle yapılan üst GIS endoskopisinde traktusun herhangi bir yerinde yerleşik, özellikle ortası göbekli, lümene doğru mukozal kabarılklk gösteren subepitelyal lezyonlarda ektopik pankreas akılda bulundurulmalıdır. Bu lezyonlardan mukozal patolojilerin ayırt edilmesi için rutin endoskopik biyopsi alınması öncelikli olarak yapılması gereken işlemdir. Ayrıca tanıyı doğrulamak için ileri görüntüleme yöntemlerinden spiral BT kullanılabileceği gibi daha önemlisi EUS

\section{KAYNAKLAR}

1. Christodoulidis G, Zacharoulis D, Barbanis S, et al. Heterotopic pancreas in the stomach: A case report and literature review. World J Gastroenterol 2007; 13: 6098-100.

2. Gokhale U, Nanda A, Pillai R, Al-Layla D. Heterotopic pancreas in the stomach: A case report and a brief review of the literature. JOP 2010; 11 255-7.

3. Jiang L, Xu J, Wang W, et al. Gastric outlet obstruction caused by heterotopic pancreas: A case report and a quick review: World J Gastroenterol 2008; 14: 6757-9

4. Lambert AW, Dale RF. A difficult case of pancreatitis. J R Soc Med 1997; 90: 44-5.

5. Khashab M, Cummings O, DeWitt J. Ligation-assisted endoscopic mucosal resection of gastric heterotopic pancreas. World J Gastroenterol 2009; 15: 2805-8.

6. Mizrak D, Bektaş M, Kaygusuz G, et al. Gastric aberrant pancreas. Turk J Gastroenterol 2010; 21: 68-9.

7. Inoue $\mathrm{Y}$, Hayashi $\mathrm{M}$, Arisaka $\mathrm{Y}$, et al. Adenocarcinoma arising in a heterotopic pancreas (Heinrich type III): A case report. J Med Case Rep 2010; 4: 39.

8. Hlavaty T, Lukac L, Vyskocil M, Galbavy S. Heterotopic pancreas in gastric antrum with macroscopic appearance of gastric polyp. Bratisl Lek Listy 2002; 103: 117-20

9. Hudok J, Wanner H, Reilly C. Acute massive gastro-intestinal hemorrhage associated with pancreatic heterotopic tissue of the stomach. Ann Surg 1956; 143: 121-5

10. Küçük G, Durgun V. Mide kanserini taklit eden heterotopik pankreas: Olgu sunumu. Cerrahpaşa Tıp Dergisi 2009; 40: 38-40

11. Watanabe K, Irisawa A, Hikichi T, et al. Acute inflammation occurring in gastric aberrant pancreas followed up by endoscopic ultrasonography. World J Gastrointest Endosc 2012; 4: 331-4.

12. Trifan A, Târcoveanu E, Danciu M, et al. Heterotopic Pancreas: An unusual case and review of the literature. J Gastrointestin Liver Dis 2012 21: 209-12

13. Cengiz C, Oğuz D, Yuyucu Y, et al. Gastrointestinal stromal tümörü taklit eden sıradışı bir gastrik ektopik pankreas olgusu. Endoskopi 2010; 18: 41-3.

14. Patil P, Shenoy V, Rao P. Aberrant pancreatic tissue causing gastric ulcer and pyloric obstruction. Indian Pediatr 1995; 32: 930-2.

15. Rubbia-Brandt L, Huber O, Hadengue A, Frossard JL. An unusual case of gastric heterotopic pancreas. JOP 2004; 5: 484-7.

16. Bromberg S, Neto C, Borges A, et al. Pancreatic heterotopias: clinicopathological analysis of 18 patients. Rev Col Bras Cir 2010; 37: 413-9. ile değerlendirilerek lezyonun köken aldığı duvar katmanı, mukoza ve muskuler tabaka ile ilişkisi değerlendirilmelidir. Asemptomatik hastalarda endoskopik takip yeterli olurken, semptomatik vakalarda semptomların şiddeti ve EP dokusu ile ilişkisine göre endoskopik veya cerrahi tedavi alternatifleri düşünülmelidir.

Sonuç olarak, EP nadir olmasına rağmen, çeşitli gastrointestinal lezyonların ayırıcı tanısında akılda tutulmalıdır (16).

17. Yuan Z, Chen J, Zheng Q.et al. Heterotopic pancreas in the gastrointestinal tract. World J Gastroenterol 2009: 15(29): 3701-3703.

18. Hickman D, FREY C, Sacramento M et al. Adenocarcinoma arising in gastric heterotopic pancreas. West J Med. 1981: 135. 57-62

19. Gupta M, Karlitz J, Raines D, et al. Heterotopic pancreas. J La State Med Soc. $2010 ; 162: 310-3$

20. Temes T, Griffin N, CNP. The cantankerous pancreas. Gastroenterol Hepatol 2007; 3: 941-2.

21. Rao R, Kamlesh Y, Pallav G, et al. Ectopic pancreas presenting as periampullary tumor with obstructive jaundice and pruritus is a rare diagnostic and therapeutic dilemma: A case report. J Pancreas. 2011; 12: 607-9.

22. Karahan Ö, Kahrıman G, Soyuer I, et al. Distal koledokta yerleşen heterotopik pankreatik dokunun MR kolanjiopankreatografi bulguları. Diagn Interv Radiol 2006; 12: 180-2

23. Yan M, Wang Y, Tian Y, Lin Y. Adenocarcinoma arising from intrahepatic heterotopic pancreas: A case report and literature review. World J Gastroenterol 2012; 18: 2881-4.

24. Canbaz H, Colak T, Düșmez D.ve ark. An unusual cause of acute abdomen: Mesenteric heterotopic pancreatitis causing confusion in clinical diagnosis. Turk J Gastroenterol 2009; 20: 142-5.

25. Mayes R. Pancreatic heterotopia presenting as a gastric submucosal lesion. Ulster Med J 2010; 79: 100-5.

26. Kantar F, Akarsu M, Atilla K, et al. Ectopic pancreas presenting with intractable diarrhea: case report. Turk J Gastroenterol 2011; 22: 426-9.

27. Erkan N, Vardar E, Vardar R. Heterotopic pancreas: report of two cases. J Pancreas 2007; 8: 588-91.

28. Hlavaty T, Lukac L, Vyskocil M, et al. Heterotopic pancreas in gastric antrum with macroscopic appearance of gastric polyp. Bratisl Lek Listy 2002; 103: 117-20.

29. Galloro G, Napolitano V, Magno L, et al. Diagnosis and therapeutic management of cystic dystrophy of the duodenal wall in heterotopic pancreac: A case report and revision of the literature. J Pancreas 2008; 9: 725-32

30. Cankorkmaz L, Atalar M, Müsliheddinoğlu A, et al. Ektopik pankreas dokusunun sebep olduğu bir invajinasyon: Olgu sunumu. C. U. Tip Fakültesi Dergisi 2005; 27: 129-32.

31. Sadeghi R, Godambe A, Shienbaum A. Premalignant gastric heterotopic pancreas. Gastroenterol Hepatol 2008; 3: 218-22.

32. Ryu D, Kim G, Park D, et al. Endoscopic removal of gastric ectopic pancreas: An initial experience with endoscopic submucosal dissection. World J Gastroenterol 2010; 16: 4589-93. 